\title{
ANALISIS PEMBIAYAAN INVESTASI PADA PEMBANGUNAN PERUMAHAN TAMAN KARANGBAHAGIA TAHAP 1 KABUPATEN BEKASI, JAWA BARAT
}

\author{
Rossy Khairinisa'), I Nyoman Dita Pahang Putra'), dan Anna Rumintang ${ }^{1)}$ \\ 1) Teknik Sipil, Universitas Pembangunan Nasional "Veteran" Jawa Timur, Surabaya, \\ Jawa Timur \\ khairinisarossy@gmail.com
}

\begin{abstract}
In the development planning of a project, a financial analysis is needed that indicates the investment process of the project is feasible. One of the most important aspects of the investment process is the composition of financing. Funding can be divided into two, namely from loans and equity. The study was conducted on the Karangbahagia Park Housing development project in Bekasi, West Java. The purpose of this study was to determine the sensitivity of three different financing compositions. This research was conducted using the Discounted Cash Flow method to calculate the project valuation. Then the investment feasibility is measured by NPV (Net Present Value), IRR (Internal Rate Return), BEP(BreakEven Point) and ROI (Return on Investment) indicators. The three financing compositions to be investigated are 70\% loan: $30 \%$ equity. $30 \%$ loan: $70 \%$ equity and 50\% loan: $50 \%$ equity. The results of the composition sensitivity analysis show that in the composition of 30\% loan: 70\% equity NPV reached a positive number of IDR.17,485,230,641.00 and IRR $38 \%$. While on the composition of 70\% loan: $30 \%$ equity NPV negative and IRR reached values of IDR.9,126,201,503.00 and 2\%. In the composition of 50\% loan: $50 \%$ equity, namely NPV reached a value of IDR.4,179,514,569.00 and IRR 21\%. BEP occurs after one year and ten months and Return on Investment yields a figure of $16.71 \%$ from the composition of $30 \%$ loan: $70 \%$ loan.
\end{abstract}

Keywords: Project Valuation, NPV, IRR, BEP, ROI 


\begin{abstract}
ABSTRAK
Pada perencanaan pembangunan sebuah proyek diperlukan suatu analisis finansial yang menandakan proses investasi proyek tersebut layak dilakukan. Salah satu aspek yang paling penting dalam proses investasi adalah komposisi pembiayaan. Pembiayaan dapat dibagi menjadi dua yaitu dari pinjaman (loan) dan modal sendiri (equity). Penelitian dilakukan pada proyek pembangunan Perumahan Taman Karangbahagia di Kabupaten Bekasi, Jawa Barat. Tujuan penelitian ini adalah untuk mengetahui sensitivitas dari tiga komposisi pembiayaan yang berbeda. Penelitian ini dilakukan dengan menggunakan metode Discounted Cash Flow untuk menghitung project valuationnya. Kemudian kelayakan investasi diukur berdasarkan indikator NPV (Net Present Value), IRR (Internal Rate Return), BEP (Break Even Point) dan ROI (Return on Investment). Tiga komposisi pembiayaan yang akan diteliti sesitivitasnya adalah $70 \%$ loan : $30 \%$ equity. $30 \%$ loan : $70 \%$ equity dan 50\% loan : 50\% equity. Hasil analisis sensitivitas komposisi menunjukan bahwa pada komposisi 30\% loan : 70\% equity NPV mencapai angka positif sebesar Rp.17,485,230,641.00 dan IRR 38\%. Sementara pada komposisi 70\% loan : 30\% equity NPV negatif dan IRR mencapai nilaisebesar Rp.9,126,201,503.00 dan 2\%. Pada komposisi 50\% loan : 50\% equity yaitu NPV mencapai nilai negatif yaitu sebesar Rp.4,179,514,569.00 dan IRR 21\%. BEP terjadi setelah satu tahun sepuluh bulan dan Return on Investment menghasilkan angka $16.71 \%$ dari komposisi $30 \%$ loan : $70 \%$ loan.
\end{abstract}

Kata kunci: evaluasi proyek, NPV, IRR, BEP, ROI 


\section{PENDAHULUAN}

DKI Jakarta merupakan kawasan metropolitan dengan jumlah penduduk yang tinggi dibandingkan daerah lain di Indonesia. Pertumbuhan penduduk yang semakin meningkat ini diikuti oleh permintaan akan rumah tinggal. Menurut Putra (2018), cepatnya perkembangan infrastruktur suatu daerah akan mengakibatkan padatnya populasi penduduk daerah tersebut juga. Menurut Cahyadi \& Sutiari (2009), pertumbuhan penduduk yang semakin meningkat tidak dapat berjalan beriringan dengan ketersediaan lahan untuk tempat tinggal karena 92\% wilayah Jakarta telah menjadi kawasan terbangun. Maka dari itu kota penyangga seperti Bogor, Tangerang, dan Bekasi dijadikan kawasan pemukiman. Hal ini lah yang membuat banyak developer tertarik untuk berinvestasi pada housing estate.

Menurut Anastasia, Yakobus \& Susilawati (2001), investasi housing estate membutuhkan biaya dan memiliki resiko yang besar. Untuk mengurangi adanya kemungkinan resiko merugi, pengembang melakukan analisis studi kelayakan proyek. Salah satu metode untuk menganalisis kelayakan investasi adalah discounted cash flow (DCF). Menurut Shrieves dan Junior (2001), DCF adalah salah satu metode analisis investasi yang digunakan untuk studi kelayakan dan pengambilan keputusan.

Beberapa nilai akhir yang dihasilkan dari perhitungan discounted cash flow adalah NPV (Net Present Value) dan IRR (Internal Rate Return). Kedua nilai ini merupakan indikator dalam menilai kelayakan sebuah investasi. Selain mengukur kelayakan investasi, salah satu analisis yang dilakukan adalah analisis sensitivitas. Menurut Bannerman (1993), ketidakpastian dalam property appraisal tidak dapat dihindari. Analisis ini dilakukan untuk menentukan ketahanan sebuah keputusan terhadap suatu perubahan. Perubahan ini dapat bermacam-macam seperti perubahan pada tingkat suku bunga, pendapatan dan hasil penjualan.

Tujuan dari penelitian ini adalah kelayakan investasi proyek dapat diketahui dengan perhitungan project valuation. Kemudian menganalisis sensitivitas dari komposisi pembiayaan. Analisis breakeven point dilakukan dengan komposisi dengan NPV paling baik dengan memperhitungkan pendapatan, pengeluaran dan debt service. Kemudian dengan komposisi tersebut di analisis nilai return on investment nya. 


\section{KAJIAN PUSTAKA}

\section{$2.1 \quad$ Net Present Value (NPV)}

Menurut Prastiwi dan Utomo (2013), konsep dari net present value adalah mendiskonto nilai arus kas ke nilai sekarang.

$\mathrm{NVP}=-\mathrm{kt}+\frac{\mathrm{b} 1-\mathrm{c} 1}{(1+\mathrm{i})}+\frac{\mathrm{b} 2-\mathrm{c} 2}{(1+\mathrm{i})^{2}}+\ldots+\frac{\mathrm{bn}-\mathrm{cn}}{(1+\mathrm{i})^{\mathrm{n}}} \ldots$.

dimana:

NPV : nilai sekarang bersih

$\mathrm{Kt} \quad$ : nilai kapital yang digunakan pada periode investasi

b1, b2, bn: penerimaan pada tahun ke-1 hingga tahun ke-n

c1, c2, cn : pengeluaran pada tahun ke-1 hingga tahun ke-n

i : tingkat diskonto rate

Apabila NPV > 0, maka usulan investasi diterima. Sementara apabila NPV $<0$, usulan investasi belum dapat diterima dan harus dikaji ulang.

\subsection{Internal Rate Return (IRR)}

Menurut Long (2011), Internal Rate Return (IRR) adalah tingkat diskonto yang saat diterapkan ke arus pemasukan proyek, menghasilkan present value yang sama dengan nilai investasi. Hal ini selaras dengan pernyataan oleh Prastiwi dan Utomo (2013), metode IRR adalah salah satu cara untuk mencari suatu tingkat bunga yang menyamakan jumlah yang diharapkan akan diterima dengan jumlah investasi yang harus dikeluarkan. Perhitungan IRR akan lebih mudah apabila menggunakan program bantu spreadsheet seperti Microsoft Excel.

$$
\operatorname{IRR}=\sum_{\mathrm{t}=\mathrm{n}}^{\mathrm{n}} \frac{(\mathrm{c}) \mathrm{t}}{(1+\mathrm{i})^{\mathrm{t}}}-\sum_{\mathrm{t}=\mathrm{n}}^{\mathrm{n}} \frac{(\mathrm{C} 0) \mathrm{t}}{(1+\mathrm{i})^{\mathrm{t}}}=0
$$

dimana:

IRR : arus pengembalian internal

(c)t : aliran kas masuk tahun ke $\mathrm{n}$

(C0)t : aliran kas keluar tahun ke n

n : periode investasi

i : tingkat diskonto rate

t : tahun

Apabila IRR >discount factor, maka usulan investasi diterima. Sedangkan apabila IRR < discount factor maka usulan investasi belum dapat diterima dan harus dikaji ulang.

\subsection{Return on Investment (ROI)}

Menurut Hamed (2019), return on investment merupakan sebuah cara yang dilakukan investor unutk memperkirakan dan mengevaluasi performa dari sebuah investasi.

$$
\mathrm{ROI}=\frac{\text { annual cash flow }}{\text { total cash invested }} \times 100 \%
$$

\subsection{Analisis Sensitivitas}

Menurut Bannerman

(1993), ketidakpastian dalam property appraisal tidak dapat dihindari. Maka dari itu terdapat tiga metode yang dapat dilakukan untuk menanggulangi ketidakpastian tersebut 
antara lain analisis sensitivitas, analisis skenario dan analisis resiko. Analisis sensitivitas dilakukan untuk menentukan ketahanan sebuah keputusan terhadap perubahan. Perubahan ini dapat bermacammacam seperti perubahan pada tingkat suku bunga, pendapatan dan hasil penjualan.

Analisis sensitivitas pada penelitian ini dilakukan dengan mencari nilai NPV = 0 dan IRR $=$ discount factor dengan rumus interpolasi. Rumus interpolasi adalah sebagai berikut:

$$
f_{1}(x)=f\left(x_{0}\right)+\frac{f(x)-f\left(x_{0}\right)}{x_{1}-x_{0}}\left(x-x_{0}\right)
$$

\section{METODE PENELITIAN}

Metode yang akan digunakan dalam penelitian ini adalah discounted cash flow (DCF). Metode ini akan digunakan terhadap tiga komposisi pembiayaan yang berbeda yaitu $70 \%$ loan : $30 \%$ equity, $50 \%$ loan : 50\% equity dan 30\% loan : $70 \%$ equity. Ketiga komposisi tersebut dipilih berdasarkan buku Charles Long berjudul Finance for Real Estate Development yang menyebutkan bahwa pinjaman akan membiayai sekitar 50\% hingga 80\% dari total biaya proyek. Kemudian ketiga pembiayaan tersebut dianalisis sensitivitasnya dengan formulasi interpolasi. Nilai NPV dan IRR akan didapatkan dalam akhir perhitungan ini.
Kedua nilai tersebut akan menandakan kelayakan dari proyek ini.

Data yang digunakan dalam penelitian ini adalah data sekunder yang didapatkan dari developer berupa project cost, rincian harga satuan biaya konstruksi, harga satuan jual, asumsi penjualan bulanan dansite plan.

\section{HASIL DAN PEMBAHASAN}

\subsection{Analisis Biaya Pengembangan}

Analisis biaya pengembangan didapat dari data sekunder yang dikeluarkan oleh developer. Biaya-biaya ini dikeluarkan secara bertahap sesuai waktu aktivitas tersebut dilakukan. Secara garis besar biaya pengembangan mulai dikeluarkan pada tahun 2015 untuk melakukan pengadaan tanah. Pada tahun 2016 sejumlah biaya dikeluarkan untuk pengurusan perizinan dan legalitas, perencanaan, pematangan lahan, sebagian untuk infrastruktur listrik dan memulai konstruksi blok B. Tahun 2017 pengeluaran biaya pengembangan masih berlanjut untuk pengembangan infrastruktur listrik, jalan dan jembatan. Selain itu pada tahun 2017, pengembangan blok $\mathrm{B}$ memasuki tahun kedua dan developer memulai pengembangan blok $\mathrm{C}$. Tahun keempat pengembangan, developer memulai konstruksi blok A. Tahun 2018 juga 
merupakan tahun pengembangan terakhir untuk blok B, tahun pengembangan kedua untuk blok $\mathrm{C}$ dan developer mulai membangun sejumlah unit komersial berupa ruko pada tahun ini. Tahun kelima yaitu tahun 2019 merupakan tahun pengembangan terakhir untuk blok $\mathrm{A}$ dan blok C. Rekapitulasi biaya pengembangan dapat dilihat pada Tabel 1.

\subsection{Analisis Biaya Operasioal}

Biaya operasional merupakan biaya yang dikeluarkan selama proses investasi berlangsung. Biaya-biaya yang dianalisis adalah biaya penggunaan listrik, air, gaji karyawan dan biaya marketing. Rekapitulasi biaya operasional dapat dilihat pada Tabel 2.

\subsection{Analisis Pendapatan}

Analisis pendapatan dilakukan dengan mengasumsikan rencana penjualan rumah. Penjualan rumah dilakukan bertahap selama empat tahun dengan asumsi pada tahun 2016 developer mulai menjual 50\% dari jumlah keseluruhan unit blok B. Kemudian pada tahun kedua yaitu tahun 2017, diasumsikan penjualan blok B dilanjutkan sejumlah $25 \%$ sementara penjualan blok $\mathrm{C}$ dimulai dengan menjual $50 \%$ dari keseluruhan unit. Pada tahun ketiga yaitu 2018 penjualan blok B telah selesai dengan menjual $25 \%$ dari total keseluruhan unit. Penjualan blok $\mathrm{C}$ juga mulai memasuki pada $25 \%$ unit selanjutnya dan developer mulai menjual $60 \%$ dari total keseluruhan unit blok A. Tahun terakhir penjualan yaitu pada tahun 2019, developer menjual 25\% unit terakhir di blok $\mathrm{C}$ dan $40 \%$ unit di blok A. Selain itu pada tahun ini developer juga menjual seluruh unit ruko. Asumsi penjualan unit rumah dan ruko dapat dilihat pada tabel 3. Jumlah pendapatan tahunan dapat diketahui dari Tabel 3. Pendapatan tahunan dapat dilihat pada Tabel 4.

\subsection{Analisis Investasi}

\subsubsection{Analisis Net Operating Income}

Net operating income adalah salah satu komponen penting dalam perhitungan analisis kelayakan investasi dengan metode project valuation. Menurut Long (2011), net operating income didapatkan setelah suatu proyek mendapatkan pendapatan tahunan atau yang disebut effective gross income (EGI). Cara mendapatkan nilai net operating income adalah dengan menjumlahkan biaya pengembangan dan biaya operasional. Kemudian kedua biaya tersebut dikurangi dengan pendapatan tahunan atau effective gross income. Analisis net operating income dapat dilihat pada Tabel 5. 


\subsubsection{Analisis Modal Pengembangan}

Analisis ini dilakukan sebagai langkah untuk mengetahui modal yang dibutuhkan oleh pengembang serta mengetahui sensitivitas kapitalisasinya. Modal yang harus disediakan oleh pengembang akan diketahui setelah seluruh biaya pengeluaran (biaya pengembangan dijumlah dengan biaya operasional) selama lima tahun masa pegembangan diketahui. Hasil dari perhitungan modal pengembangan adalah Rp.83,077,647,802.

\subsubsection{Analisis Kelayakan Investasi}

Analisis kelayakan investasi atau project valuation dilakukan dengan metode discounted cash flow. Analisis ini dilakukan untuk mengetahui sensitivitas kapitalisasi berdasarkan komposisi yang sudah ditetapkan. Suku bunga equity diasumsikan sebesar $15 \%$ sementara suku bunga loan diasumsikan sebesar $12.5 \%$ Hasil analisis project valuation ini adalah pada komposisi 70\% loan: $30 \%$ equitymemiliki NPV negatif yaitu Rp 9,126,201,503 dan IRR $2 \%$. Kemudian pada komposisi kedua yaitu $30 \%$ loan dan $70 \%$ equity memiliki NPV Rp 17,485,230,641 dan IRR 38\%. Pada komposisi terakhir yaitu 50\% loan dan 50\% equity memiliki NPV dan IRR sebesar Rp 4,179,514,569 dan 21\%. Kesimpulan dari perhitungan kelayakan investasi degan tiga komposisi modal adalah komposisi yang dianggap layak untuk diterima investasinya adalah $30 \%$ loan: $70 \%$ equity karena memiliki nilai NPV $<0$ dan IRR $<$ discount factor.

\subsubsection{Analisis Sensitivitas}

Analisis sensitivitas dilakukan dengan formulasi interpolasi untuk mencari angka komposisi loan dengan NPV $=0$. Hasil interpolasi menunjukkan nilai sensitivitas sebesar $62.56 \%$.

\subsubsection{Analisis Break Even Point}

Perhitungan break even point dilakukan dengan pendekatan pendapatan dan pengeluaran. Pengeluaran yang dihitung adalah keselruhan biaya pengembangan dan biaya operasional. Break even point terjadi setelah satu tahun sepuluh bulan.

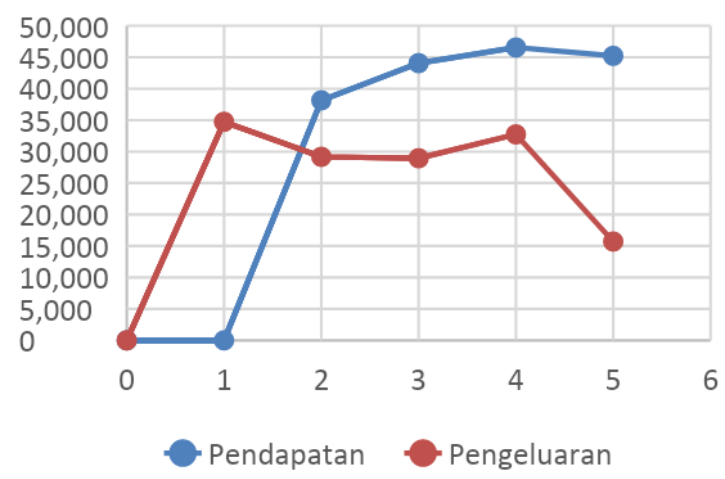

Gambar 1. Grafik BEP 
Tabel 1. Rekapitulasi Biaya Pengembangan

\begin{tabular}{|c|c|c|c|c|c|}
\hline \multirow{2}{*}{ Aktivitas } & \multicolumn{5}{|c|}{ Biaya Pengembangan Tiap Tahun (dalam juta rupiah) } \\
\hline & 2015 & 2016 & 2017 & 2018 & 2019 \\
\hline Pengadaan Lahan & 27,750 & & & & \\
\hline Legalitas & & 4,004 & & & \\
\hline Perencanaan & & 450 & & & \\
\hline Pematangan Lahan & & 6,013 & & & \\
\hline Infrastruktur Listrik & & 265 & 1,521 & & \\
\hline Infrastruktur Jalan & & & 5,171 & & \\
\hline Infrastruktur Jembatan & & & 700 & & \\
\hline Infrastruktur Saluran dan Pond & & & 2,559 & & \\
\hline Konstruksi Blok A & & & & 5,400 & 4,320 \\
\hline Konstruksi Blok B & & 9,003 & 4,596 & 4,675 & \\
\hline Konstruksi Blok C & & & 4,874 & 2,457 & 2,417 \\
\hline Konstruksi Ruko & & & & 10,584 & \\
\hline Total & 27,750 & 19,735 & 19,421 & 23,116 & 6,737 \\
\hline
\end{tabular}

Tabel 2. Rekapitulasi Biaya Operasional

\begin{tabular}{lrrrr}
\hline \multicolumn{1}{c}{ Aktivitas } & \multicolumn{4}{c}{ Biaya Operasional Tiap Tahun (Rp) } \\
& \multicolumn{1}{c}{2016} & 2017 & \multicolumn{1}{c}{2018} & \multicolumn{1}{c}{2019} \\
\hline Listrik & 410,911 & 427,859 & 427,859 & 427,859 \\
Air & 401,760 & 401,760 & 401,760 & 401,760 \\
Gaji Karyawan & $1,350,000,000$ & $1,350,000,000$ & $1,350,000,000$ & $1,350,000,000$ \\
Pemasaran & $1,103,445,000$ & $1,191,645,000$ & $1,287,464,360$ & $641,485,740$ \\
\hline Total & $2,454,257,671$ & $2,542,474,619$ & $2,638,293,979$ & $1,992,315,359$ \\
\hline
\end{tabular}

Tabel 3. Skema Penjualan

\begin{tabular}{ccccc}
\hline Keterangan & 2016 & 2017 & 2018 & 2019 \\
\hline Blok A & & 46 & 30 \\
$36 / 72$ & & 11 & 8 \\
$36 / 84$ & & 2 & 1 \\
$36 / 85$ & & & 1 \\
$36 / 81$ & & & 1 \\
$36 / 86$ & & & 1 \\
$36 / 87$ & & & 1 \\
$36 / 104$ & & & 1 \\
$36 / 105$ & & & 1 \\
$36 / 125$ & & & 1 \\
$36 / 133$ & & & 1 \\
$36 / 136$ & & & & \\
$36 / 137$ & & & \\
Blok B & & & \\
$27 / 60$ & 122 & & \\
$27 / 62$ & & & \\
$27 / 70$ & 36 & 18 & & \\
$27 / 110$ & 1 & & & \\
Blok C & & & \\
$27 / 60$ & & 159 & & \\
$27 / 70$ & & & & \\
Ruko & & & & \\
\hline
\end{tabular}


Tabel 4. Pendapatan Tahunan

\begin{tabular}{|c|c|c|c|c|}
\hline Keterangan & 2016 & 2017 & 2018 & 2019 \\
\hline \multicolumn{5}{|l|}{ Blok A } \\
\hline $36 / 72$ & & & $10,901,865,600$ & $7,267,910,400$ \\
\hline $36 / 84$ & & & $2,834,906,400$ & $1,889,937,600$ \\
\hline $36 / 85$ & & & $498,952,000$ & $249,476,000$ \\
\hline $36 / 81$ & & & & $246,276,000$ \\
\hline $36 / 86$ & & & & $250,276,000$ \\
\hline $36 / 87$ & & & & $251,076,000$ \\
\hline $36 / 104$ & & & & $264,676,000$ \\
\hline $36 / 105$ & & & & $265,476,000$ \\
\hline $36 / 125$ & & & & $281,476,000$ \\
\hline $36 / 133$ & & & & $287,876,000$ \\
\hline $36 / 136$ & & & & $288,676,000$ \\
\hline $36 / 137$ & & & & $291,076,000$ \\
\hline \multicolumn{5}{|l|}{ Blok B } \\
\hline $27 / 60$ & $32,707,500,000$ & $17,202,000,000$ & $17,202,000,000$ & \\
\hline $27 / 62$ & $143,400,000$ & & & \\
\hline $27 / 70$ & $5,094,000,000$ & $2,754,000,000$ & $2,907,000,000$ & \\
\hline $27 / 110$ & $201,000,000$ & & & \\
\hline \multicolumn{5}{|l|}{ Blok C } \\
\hline $27 / 60$ & & $22,419,000,000$ & $11,280,000,000$ & $11,280,000,000$ \\
\hline $27 / 70$ & & $1,683,000,000$ & $918,000,000$ & $765,000,000$ \\
\hline Ruko & & & & $21,340,000,000$ \\
\hline Total & $38,145,900,000$ & $44,058,000,000$ & $46,542,724,000$ & $45,219,208,000$ \\
\hline
\end{tabular}

Tabel 5. Analisis Net Operating Income (dalam ribu rupiah)

\begin{tabular}{|c|c|c|c|c|c|c|}
\hline Keterangan & 2014 & 2015 & 2016 & 2017 & 2018 & 2019 \\
\hline Effective Gross Income & & & $31,527,000$ & $34,047,000$ & $39,915,724$ & $41,792,258$ \\
\hline Pengadaan Lahan & & $27,750,005$ & & & & \\
\hline Legalitas & & & $4,004,400$ & & & \\
\hline Perencanaan & & & 450,000 & & & \\
\hline Pematangan Lahan & & & $6,012,550$ & & & \\
\hline Infrastruktur Listrik & & & 264,955 & $1,520,700$ & & \\
\hline Infrastruktur Jalan & & & & $5,171,320$ & & \\
\hline Infrastruktur Jembatan & & & & 700,000 & & \\
\hline $\begin{array}{l}\text { Infrastruktur Saluran \& } \\
\text { Pond }\end{array}$ & & & & $2,559,000$ & & \\
\hline Konstruksi Blok A & & & & & $5,400,000$ & $4,320,000$ \\
\hline Konstruksi Blok B & & & $9,003,150$ & $4,596,210$ & $4,675,455$ & \\
\hline Konstruksi Blok C & & & & $4,873,568$ & $2,456,595$ & $2,416,973$ \\
\hline Konstruksi Ruko & & & & & $10,584,000$ & \\
\hline Listrik & & & 411 & 428 & 428 & 428 \\
\hline Air & & & 402 & 402 & 402 & 402 \\
\hline Gaji Karyawan & & & $1,350,000$ & $1,350,000$ & $1,350,000$ & $1,350,000$ \\
\hline$\underline{\text { Pemasaran }}$ & & & $1,103,445$ & $1,191,645$ & $1,287,464$ & 641,486 \\
\hline $\mathrm{NOI}$ & & $(27,750,005)$ & $14,246,203$ & $17,168,677$ & $19,437,968$ & $37,047,601$ \\
\hline
\end{tabular}




\subsubsection{Analisis Return on Investment}

Perhitungan dilakukan terhadap salah satu komposisi modal yaitu komposisi $30 \%$ loan dan $70 \%$ equity. Komposisi ini dipilih karena dianggap memiliki nilai pengembalian yang paling baik karena nilai NPV dan IRR lebih besar dari komposisi lainnya. Berikut ini merupakan perhitungan ROI:

$$
\begin{aligned}
\text { ROI } & =\frac{\text { Rp. } 13,882,932,350.00}{\text { Rp. } 83,077,647,802.00} \times 100 \% \\
& =16.71 \%
\end{aligned}
$$

\section{SIMPULAN}

Hasil dari analisis project valuation menunjukan komposisi pertama yaitu $70 \%$ loan dan $30 \%$ equity memiliki NPV negatif Rp 9,126,201,503 dan IRR 2\%. Kemudian pada komposisi kedua yaitu 30\% loan dan $70 \%$ equity memiliki NPV Rp 17,485,230,641 dan IRR 38\% komposisi terakhir yaitu $50 \%$ loan dan $50 \%$ equity memiliki NPV dan IRR sebesar Rp.4,179,514,569.00 dan 21\%. Kemudian analisis break-even point terjadi setelah satu tahun lebih sepuluh bulan. Selain itu nilai ROI pada komposisi 30\% loan : $70 \%$ equity sebesar $16.71 \%$

\section{DAFTAR PUSTAKA}

Anastasia, N., Yakobus, S., Susilawati, C. (2001). Analisa Investasi dalam Pengambilan Keputusan Investasi Pada Pengembangan Lapangan Golf dan Perumahan Citraraya. Jurnal Manajemen \& Kewirausahaan, 3(1), 14-33.

Bannerman, Smyly. (1993). Sensitivity Analysis for Property Appraisal. Journal of Property Valuation and Investment. 11(3), 248-256.

Cahyadi, R., Surtiari, G.A.K. (2009). Penduduk dan Pembangunan Perumahan di Jabodetabek: Tantangan Pengembangan Megapolitan Jakarta. Jurnal Kependudukan Indonesia, IV(1).

Hamed, Eman. (9 Mei 2019). Citing Internet Sources URL https://www.mashvisor.com/blog/rat e-of-return-on-a-rental-property/

Long, C. (2011). Finance for Real Estate Development. Washington: DC:Urban Land Institute.

Prastiwi, A., Utomo, C. (2013). Analisis Investasi Perumahan Green Semanggi Mangrove Surabaya. Jurnal Teknik POMITS, 2(2).

Putra, I.N.D.P., (2018). Land Value Estimation Model as Impact of Infrastructure Development in Kaliwates Jember Indonesia. International Journal of Civil Engineering and Technology, 9(11), 1016-1030.

Shrieves, R.E., Junior, J.M.W. (2001). Free Cash Flow (FCF), Economic Value Added (EVA), And Net Present Value (NPV): A Reconciliation of Variations of Discounted Cash-Flow (DCF) Valuations. The Engineering Economist: A Journal Devoted to The Problems of Capital Investment, 46(1), 33-52. 